\title{
El sistema electoral del Congreso de los Diputados español en las elecciones generales del 10 de noviembre de 2019: representación gráfica y simulaciones de reforma
}

\author{
Miguel Ángel Sevilla Duro*
}

https://doi.org/10.35242/RDE $2021 \quad 32 \quad 14$

\section{Nota del Consejo Editorial}

Recepción: 10 de febrero de 2021.

Revisión, corrección y aprobación: 5 de julio de 2021.

Resumen: El sistema electoral del Congreso de los Diputados español suele catalogarse como de proporcionalidad corregida. Las últimas elecciones generales, celebradas el 10 de noviembre de 2019, son buena muestra de cómo un sistema tachado tradicionalmente de bipartidista ha respondido ante un contexto pluripartidista sobrevenido. Este artículo pretende representar gráficamente el funcionamiento del sistema en las referidas elecciones prestando atención a sus elementos caracterizadores. Junto a esto $-\mathrm{y}$ a la luz de las principales propuestas de la doctrina- se realiza una simulación de resultados electorales alterando la circunscripción, el umbral (o barrera) electoral y la fórmula de asignación de escaños. Con todo ello se pretende poner de manifiesto la realidad actual del sistema y su hipotético funcionamiento en atención a las propuestas de reforma.

Palabras clave: Sistema de elección de diputados / Circunscripciones electorales / Umbral electoral / Barrera electoral / Escaños / Sistemas electorales / Reformas electorales / Congreso / España.

Abstract: The electoral system of the Congress of Deputies of Spain is usually classified as one of corrected proportionality. The last general elections, held on November 10, 2019, are a good example of how a former bipartisan system has responded to a new multiparty context. This article aims to graphically represent the functioning of the system in the aforementioned elections, paying attention to its characteristic elements. Together with this -and in the light of the main proposals of change-, it shows a simulation of electoral results by altering the districts, electoral threshold and method for allocating seats. The purpose is to expose the current reality of the system and its hypothetical functioning according to the reform proposals.

Key Words: System of election of deputies / Electoral districts / Electoral threshold / Seats / Electoral system / Electoral reforms / Congress / Spain.

\footnotetext{
* Español, doctorando en Derecho, correo electrónico: MiguelAngel.Sevilla@uclm.es. Profesor de Derecho Constitucional e Investigador predoctoral (FPU19/00310) en la Universidad de Castilla-La Mancha (España). Su principal línea de investigación son las relaciones de ordinación en las integraciones supraestatales.

Es Graduado en Derecho en la Universidad de Castilla-La Mancha con estancia en la Universidad de Turku (Finlandia) y Premio Extraordinario Fin de Grado al mejor expediente de la promoción; cursó el Máster Universitario en Derecho Constitucional en el Centro de Estudios Políticos y Constitucionales con mejor expediente de la promoción; en la actualidad también cursa el Máster Universitario en Abogacía en la Universidad Rey Juan Carlos.

La Sociedad Española de Excelencia Académica lo galardonó como el mejor graduado en Derecho de España del año 2019.
} 


\section{DERECHO ELECTORAL}

\section{INTRODUCCIÓN}

El elemento definitorio de la institucionalización de la representación en los sistemas democráticos es la participación electoral, por lo que su correcta articulación es premisa para el bienestar del sistema democrático. A estos efectos, son tres las funciones clásicas que desempeñan las elecciones en la democracia representativa: otorgar la representación política, formar el Gobierno y legitimar el sistema constitucional (García, 2017, p. 533).

La forma política del Estado español estipulada en la Constitución de 1978 (en adelante, CE) es la Monarquía parlamentaria (art. 1.3 CE). Ello implica que el sistema de gobierno se basa en la representación parlamentaria, que se estructura en torno a las Cortes Generales, formadas por el Congreso de los Diputados y el Senado (art. 66.1 CE). Ambas configuran un bicameralismo imperfecto ${ }^{1}$ con un sistema de elección diferenciado con el objetivo de garantizar la representación poblacional en el Congreso y la territorial en el Senado.

Cualesquiera sistemas, en línea con Douglas Rae (1971, p. 86), comparten la característica de favorecer en mayor o menor medida a los partidos mayoritarios, de forma análoga al Sheriff de Nottingham: "entregando a los grandes partidos escaños de los pequeños". La cuestión es el modo en que ello se hace, que depende de la proximidad del sistema electoral al principio mayoritario -proclive a la estabilidad y gobernabilidad facilitando que el partido más votado obtenga mayoría absoluta o relativa - 0 al proporcional -configurado para que la representación se aproxime al porcentaje de votos obtenido por cada partido-(Nohlen, 2004, pp. 110 y ss.).

En la práctica, el sistema electoral del Congreso de los Diputados está más cerca de lo mayoritario que de lo proporcional, si bien el art. 68.3 CE afirma que la elección debe atender a criterios proporcionales. Por este motivo suele ser denominado como un sistema proporcional "corregido" o "mayoritario", aunque como recuerdan Montero y Vallès podría igualmente conceptualizarse como un sistema mayoritario "restringido" o "atenuado" (1992, pp. 6-8).

Por su parte, el sistema electoral del Senado es de voto limitado en una unidad, to que implica que los electores tienen menos votos que escaños hay en juego en la circunscripción, realizándose el reparto a través de una fórmula de mayoría relativa (Montabes y Ortega, 2002).

\footnotetext{
${ }^{1}$ El diccionario panhispánico del español jurídico expone, al definir el bicameralismo, que "las dos Cámaras pueden tener un nivel semejante de competencias, supuesto en que se habla de bicameralismo perfecto, o desigual, en cuyo caso es bicameralismo imperfecto" (Real Academia Española, 2017).
} 
Durante los más de 40 años de funcionamiento del sistema electoral español ${ }^{2}$ los cambios en el sistema de partidos se han acomodado a través de los diferentes efectos provocados por la arquitectura electoral, pasando de un bipartidismo imperante hasta la primera década del s. XXI a un multipartidismo constatable tras las últimas elecciones. De este modo, tras la imposibilidad de formar gobierno después de las elecciones de abril de 2019, las decimoquintas elecciones generales democráticas de España -las cuartas en menos de cuatro años- tuvieron lugar el 10 de noviembre de 2019.

Este ensayo pretende analizar la articulación del sistema electoral del Congreso de los Diputados español en dichas elecciones en base a sus elementos característicos (ap. 2). Con ello se tratará de evaluar su funcionamiento (ap. 3) para posteriormente explorar las hipotéticas configuraciones del Congreso a la luz de las propuestas de reforma efectuadas por la doctrina (ap. 4).

\section{Representación de los elementos del sistema electoral del Congreso de los DIPUTADOS}

El sistema electoral es un mecanismo redistributivo a modo de juego de suma cero, pues la obtención de un escaño por un partido implica la imposibilidad de que ese mismo escaño sea obtenido por otro, equilibrándose así los beneficios y pérdidas de los partidos políticos.

La regulación del procedimiento electoral, fruto de la encomienda del art. $81.1 \mathrm{CE}$, se halla en la Ley Orgánica 5/1985, de 19 de junio, del Régimen Electoral General (en adelante, LOREG), que aspira a garantizar -en consonancia con su Preámbulo"la libre expresión de la soberanía popular". Por medio de esta y con una participación del 66,23 \% (5,5 puntos porcentuales menos que en las elecciones de abril del mismo año), el 10-N de 2019 se renovaron los 350 diputados del Congreso y 208 de los 265 miembros del Senado ${ }^{3}$.

\footnotetext{
${ }^{2} \mathrm{Ni}$ la Constitución ni la LOREG, que no han padecido reformas sustanciales en las últimas décadas, modificaron las reglas contenidas en el Decreto-ley de 1977, sobre Normas Electorales, previsto para las primeras elecciones democráticas, en junio de 1977 (Caciagli, 1986, cap. 3), que extendería su vigencia a las elecciones de 1979 y 1982. Ello es muestra de dos afirmaciones: que el buen funcionamiento de un sistema electoral es condición de éxito de las nuevas democracias (como España tras la Transición o Sudáfrica tras el Apartheid) y que los sistemas electorales son manipuladores en términos estadísticos, pues pequeños cambios (no realizados en España) pueden producir grandes efectos en muchas ocasiones impredecibles e indeseados (véase el ap. 4 de este trabajo).

3 El Senado español simbiotiza los modelos austriaco y norteamericano con un doble procedimiento: por un lado, se eligen 208 senadores por sufragio universal con arreglo a un sistema mayoritario corregido, circunscripción provincial e igualdad de representación (4 por provincia, a excepción de Gran Canaria, Mallorca y Tenerife, que eligen 3, y las restantes islas, Ceuta y Melilla que eligen 1); por otro lado, cada parlamento autonómico designa un senador y otro más por cada millón de habitantes (en la presente legislatura, 57). Todos ellos sin mandato imperativo.
} 


\section{DERECHO ELECTORAL}

\section{Miguel Ángel Sevilla Duro}

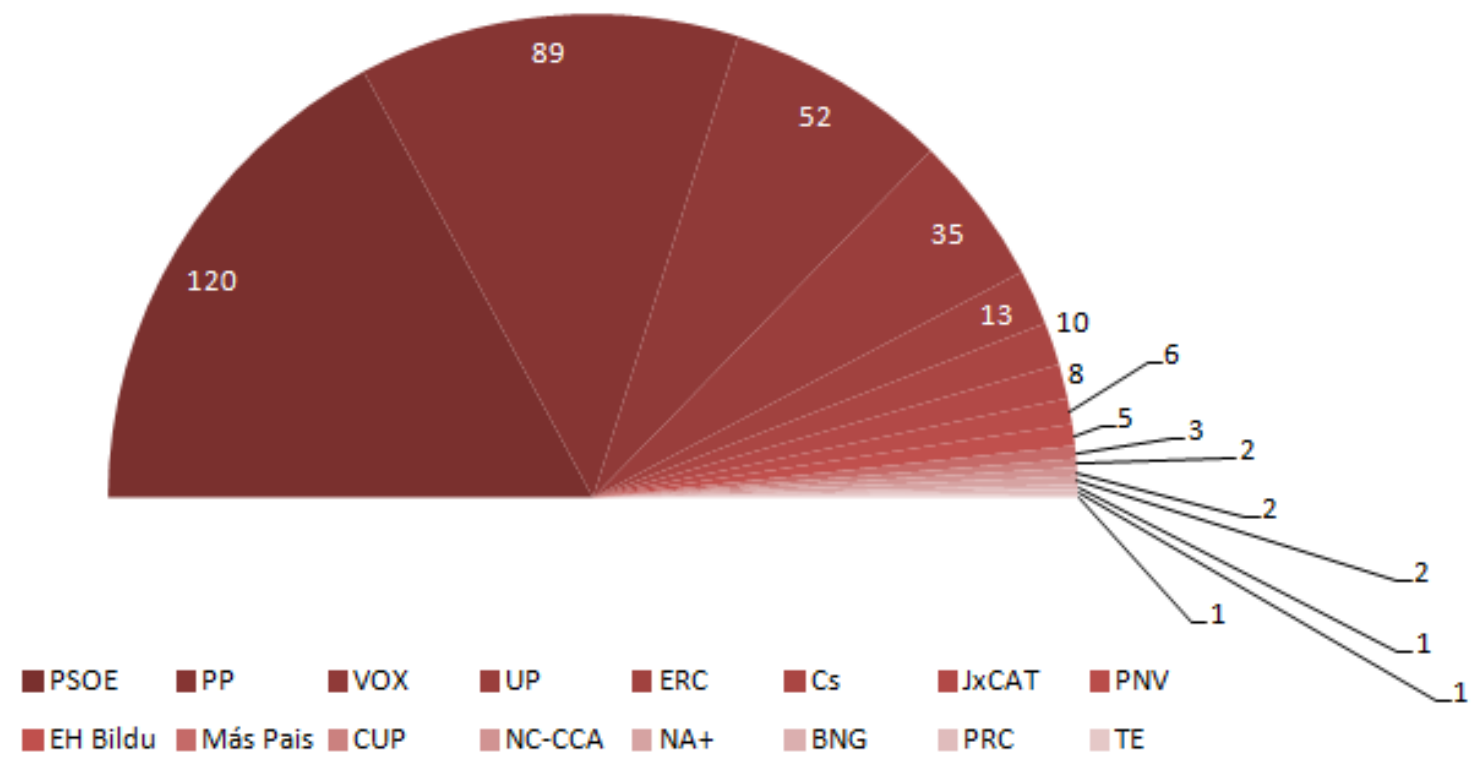

Figura 1. Número de escaños obtenidos por los partidos políticos en las elecciones generales de noviembre de 2019 al Congreso de los Diputados. Elaborada a partir de los resultados definitivos del Ministerio del Interior.

Siguiendo a Vallès y Bosch (1997), son 6 los principales elementos a considerar para el análisis de un sistema electoral: la asamblea, los distritos, el prorrateo, la fórmula electoral, la modalidad de voto y el umbral electoral.

En cuanto a la asamblea se refiere, el Congreso de los Diputados está formado por 350 escaños elegidos por sufragio universal, libre, igual, directo y secreto ${ }^{4}$. Su dimensión responde a la fórmula propuesta por Taagepera (1972), consistente en que el tamaño de la cámara se corresponda con la raíz cúbica de la población del Estado. Siendo la población de España de 47351567 habitantes, según datos del INE a 1 de julio de 2020, la raíz cúbica es 361,78. La cifra de 350 diputados, ligeramente menor, tiene correlación con la fórmula propuesta ${ }^{5}$.

Con relación a la magnitud del distrito -quizá el elemento más importante del sistema electoral (Taagepera y Shugart, 1989, p. 112)-, la circunscripción equivale a una determinada demarcación administrativa: la provincia (art. 161.1 LOREG). El reparto de los 350 escaños del Congreso se hace en 52 circunscripciones, que corresponden a las 50 provincias de España y las 2 ciudades autónomas. Ello implica

\footnotetext{
4 El art. 68.1 CE establece que el Congreso "se compone de un mínimo de 300 y un máximo de 400 diputados", concretando el art. 162.1 LOREG que "está formado por trescientos cincuenta diputados".

${ }^{5}$ Téngase en cuenta que en 1985, a la entrada en vigor de la LOREG, la población española era de 38,41 millones de habitantes (INE), por lo que la raíz cúbica era de 337,4. Ello hace pensar que la cifra de 350 diputados en el Congreso no es casual a la vista de un futuro aumento de la población.
} 


\section{DERECHOEIECTORAL}

que la magnitud media (350 escaños entre 52 distritos) sea extremadamente baja ${ }^{6}$ : solo 6,73 escaños; siendo la mediana 5 (Montero y Fernández, 2018, p. 12). Las circunscripciones son extremadamente heterogéneas, y en ellas se disputan desde 1 escaño (Ceuta y Melilla) hasta 37 (Madrid).

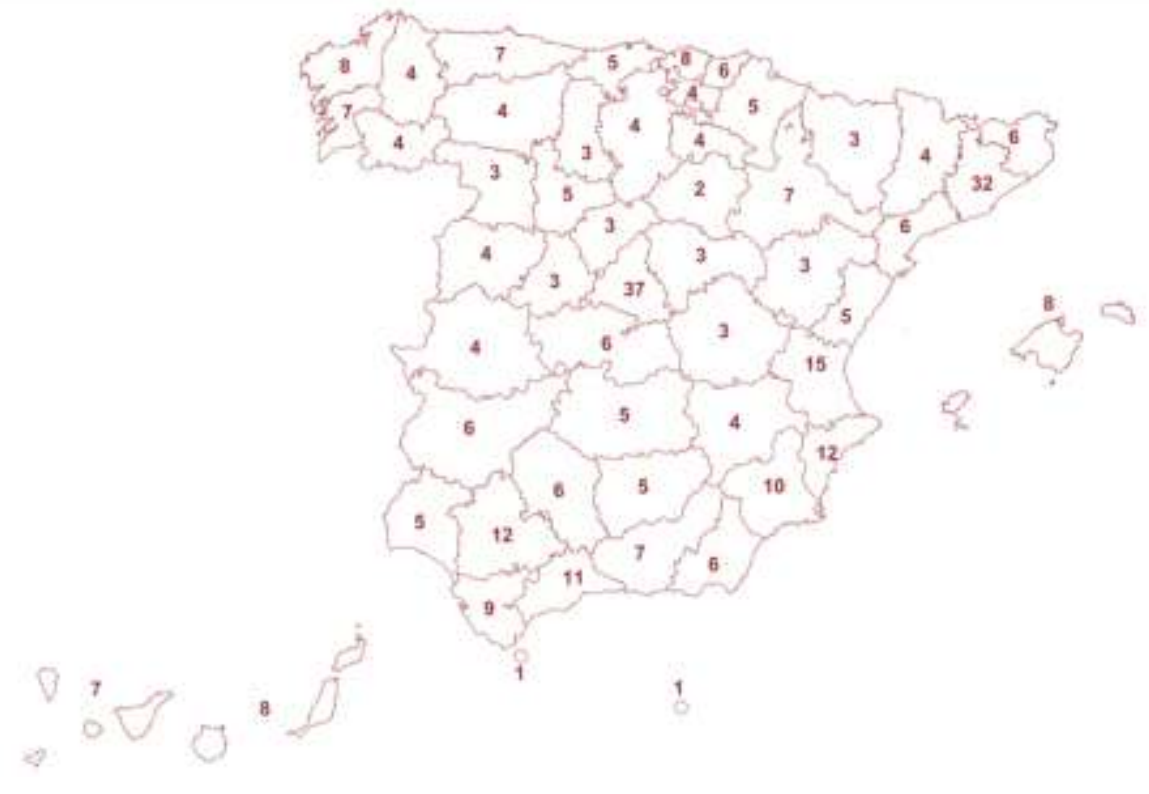

Figura 2. Distribución de escaños por circunscripción en las elecciones al Congreso de los Diputados de noviembre de 2019. Ministerio del Interior. Disponible online en https://tinyurl.com/ResultadosDefinitivos (p. 6).

Por ello, en relación con el prorrateo, esto es, la distribución de escaños por circunscripción, es indudable que existe malapportionment ${ }^{7}$, por cuanto hay una sobrerrepresentación de las circunscripciones con menor población. El art. 68.2 CE encomienda a la Ley establecer "una representación mínima inicial a cada circunscripción". En tal sentido, el art. 172.2 LOREG otorga una representación mínima de dos diputados por provincia, con la excepción de Ceuta y Melilla, a las que solo se les asigna un diputado, según el art. 68.2 CE. Así pues, 102 diputados ( 2 por cada una de las 50 circunscripciones provinciales más 2 por Ceuta y Melilla) se asignan con base territorial, mientras que los 248 diputados restantes se distribuyen en proporción a la población de cada provincia.

\footnotetext{
${ }^{6}$ Como recuerdan Montero y Fernández (2018, p. 12), desde 1945 en los sistemas electorales occidentales con fórmula D'Hondt y distritos plurinominales solo Francia en 1986 tuvo menor magnitud media; de entre los proporcionales, solamente Irlanda (VUT). Esta opción, elegida deliberadamente por el legislador, responde a intereses políticos y de estabilidad tras la Transición (pp. 8-11).

7 Disonancia entre el porcentaje de población de una circunscripción respecto de la totalidad y el porcentaje de escaños otorgados a esta. Su existencia se debe usualmente al deseo del legislador de aumentar el número de escaños del partido en el gobierno (Shugart y Taagepera, 2017, p. 61). En relación con el sistema español, vid. Alzaga (1989).
} 


\section{DERECHO EIECTORAL}

Dicha desigualdad llega hasta el punto de que España es el país número 12 con mayor malapportionment del mundo ${ }^{8}$. Como muestra, en las pasadas elecciones la provincia de Soria (89 752 habitantes y 2 escaños en juego) eligió un diputado por cada 44876 habitantes, mientras que en Madrid (6 661949 habitantes y 37 escaños en juego) se escogió un diputado por cada 180053 habitantes (4 veces más que en Soria). Esta división de prorrateo se erige como la cuarta mayor de Europa (Ong, Kasuya y Mori, 2009).

Lo relatado implica que en lugar de hacer referencia a un único sistema electoral sea tan posible como necesario afirmar que existen tres subsistemas: uno mayoritario en los distritos de 1 a 5 escaños, uno intermedio o mixto en los distritos de 6 a 9 escaños y uno proporcional en aquellos con 10 o más escaños (Penadés, 1999), tal y como se presenta en la tabla 1.

Tabla 1

Subsistemas electorales en el sistema electoral español en las elecciones de noviembre de 2019

\begin{tabular}{|c|c|c|c|c|}
\hline \multicolumn{5}{|c|}{ SUBSISTEMAS ELECTORALES } \\
\hline Características & $\begin{array}{l}\text { Mayoritario } \\
\text { (distrito de } 1 \text { a } 5 \\
\text { escaños) }\end{array}$ & $\begin{array}{c}\text { Intermedio } \\
\text { (distrito de } 6 \text { a } 9 \\
\text { escaños) }\end{array}$ & $\begin{array}{l}\text { Proporcional } \\
\text { (distrito de } 10 \text { o } \\
\text { más escaños) }\end{array}$ & Total \\
\hline \multicolumn{5}{|c|}{ Circunscripciones } \\
\hline $\begin{array}{c}\text { Número } \\
\%\end{array}$ & $\begin{array}{c}28 \\
53,85\end{array}$ & $\begin{array}{c}17 \\
32,69\end{array}$ & $\begin{array}{c}7 \\
13,46\end{array}$ & $\begin{array}{c}52 \\
100\end{array}$ \\
\hline \multicolumn{5}{|c|}{ Diputados } \\
\hline Número & 103 & 118 & 129 & 350 \\
\hline$\%$ & 29,43 & 33,71 & 36,86 & 100 \\
\hline Magnitud media & 3,68 & 6,94 & 18,43 & 6,73 \\
\hline \multicolumn{5}{|c|}{ Votantes } \\
\hline Número & 4784991 & 8404848 & 11317876 & 24507715 \\
\hline$\%$ & 19,53 & 34,29 & 46,18 & 100 \\
\hline \multicolumn{5}{|c|}{ Electores } \\
\hline Número & 7794658 & 12862855 & 16343095 & 37000608 \\
\hline$\%$ & 21,07 & 34,76 & 44,17 & 100 \\
\hline
\end{tabular}

Nota: Elaborada a partir de los criterios de Penadés (1999, p. 293). Datos de electores extraídos del INE (https://tinyurl.com/HabitantesIne). Resultados definitivos extraídos del Ministerio del Interior.

\footnotetext{
${ }^{8}$ De acuerdo con la metodología empleada por Samuels y Snyder: Malapportionment $=(1 / 2) \sum\left|s_{i}-v_{i}\right|(S i m o ́ n, 2009, p$. 185). El malapportionment del Congreso es de 0,1 ; a la cabeza de la escala se encuentra Corea del Sur con $0,21$.
} 


\section{DERECHO ELECTORAL}

La fórmula electoral aplicada en España, es decir, el sistema por el que los votos son computados, transformados en escaños y distribuidos a los partidos, es la fórmula D'Hondt (art. 163.1 LOREG), la menos proporcional dentro de los sistemas proporcionales.

Como muchos han indicado, la fórmula parece favorecer a los partidos con fuerte asentamiento en el electorado y perjudica a aquellos con menor número de votos, pero sus efectos están modulados por la dispersión del voto y la magnitud del distrito (Arnaldo, 2019). Por esta razón genera gran desproporcionalidad en las circunscripciones pequeñas (de menos de 5 escaños), una proporcionalidad moderada en las circunscripciones medianas (de 5 a 6 escaños) y una proporcionalidad considerable en las grandes (de más de 10 escaños).

En cuanto a la modalidad de voto (ballot structure), esto es, la forma en que el elector selecciona la candidatura, las elecciones al Congreso se basan en listas cerradas y bloqueadas, sin voto preferencial (arts. 46.3, 96.2, 169.2 y 172.2 LOREG), siguiendo el modelo del Decreto-ley de 1977. Dicha modalidad se adoptó por la necesidad de disipar la conflictividad interna en unos partidos en formación y una democracia frágil como la de aquel entonces (Colomer, 2004), si bien no se encuentra exenta de críticas (por todos, Almagro, 2018).

Finalmente, en cuanto al umbral (o barrera) electoral, entendido como el porcentaje mínimo de votos que debe reunir una candidatura para participar en la distribución de escaños (Vallès y Bosch, 1997), la LOREG lo fija en el tres por ciento de los votos válidos emitidos en la circunscripción (art. 173.1.a) ${ }^{9}$. Sin embargo, como bien apuntan Montero y Fernández (2018), el umbral efectivo (real) de los distritos -salvo en Madrid y Barcelona- alcanza el 10,2 por ciento, lo que lo convierte en uno de los umbrales efectivos más altos, solo superado por el sistema electoral irlandés.

Todo lo aquí expuesto ha generado efectos muy positivos en relación con la inclusividad del sistema, los claros ganadores que muestra, sus predictibles efectos y la simpleza de sus reglas. Sin embargo, ha forzado, especialmente en las circunscripciones pequeñas - más mayoritarias- a que los electores recurran al voto estratégico para evitar su "pérdida" en términos de conversión a escaños (ver figura 3 y tabla 2), y ha sido criticado por su sesgo mayoritario, pues se puede convenir en que beneficia a partir del $15 \%$ de los votos y perjudica a todos aquellos partidos que no superan dicho porcentaje, como se expone en la tabla 3 (Moreno y Oñate, 2004).

\footnotetext{
${ }^{9}$ En la práctica, solo ha intervenido en dos ocasiones: en 1989, arrebatando un escaño a ERC, y en 1993, con el CDS. Por su articulación es difícil que actúe en circunscripciones distintas a Madrid y Barcelona. Según Montero y Fernández, solamente puede funcionar en distritos de más de 24 escaños (2018, p. 15).
} 


\section{DERECHO EIECTORAL}

\section{Miguel Ángel Sevilla Duro}

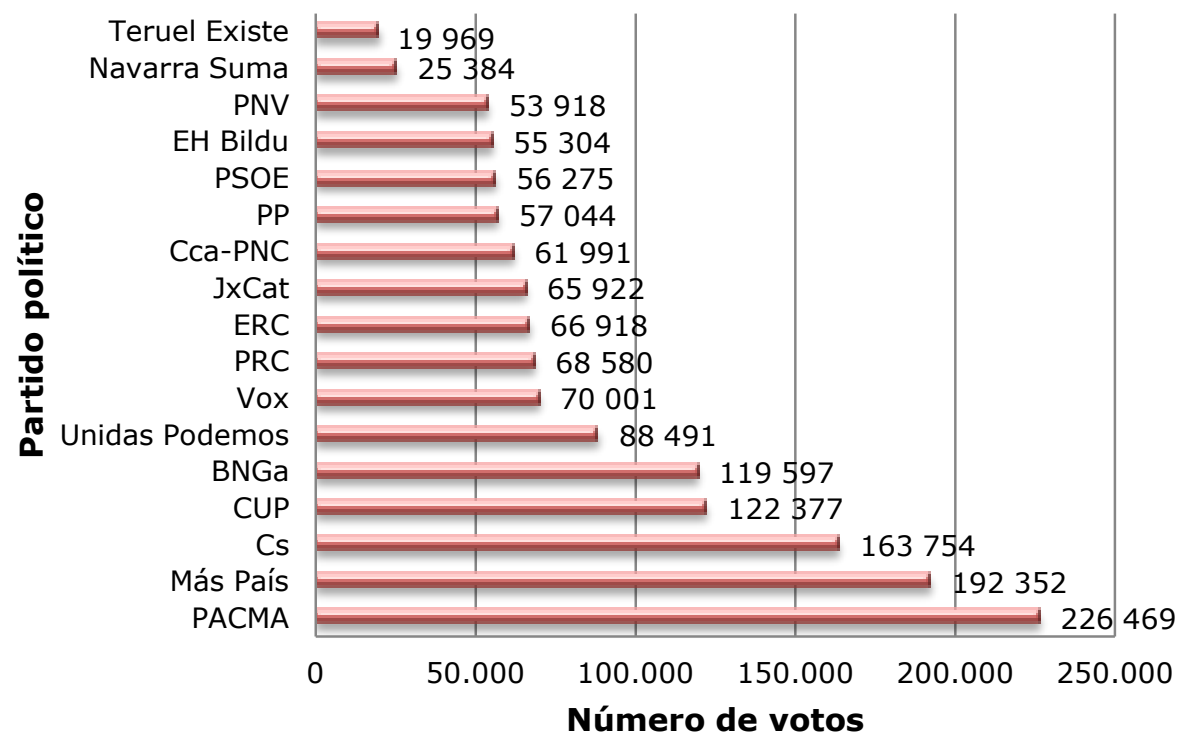

Figura 3. ¿Cuántos votos le ha costado un escaño a cada partido? Cociente entre el número total de votos y el número de escaños obtenidos ${ }^{10}$. Elaborada a partir de los datos del Ministerio del Interior.

\section{Tabla 2}

Agregado del número y porcentaje de votos que no consiguieron un escaño, por partido, en las elecciones de noviembre de 2019

\begin{tabular}{|l|c|c|}
\hline \multicolumn{1}{|c|}{ Partido } & Votos "perdidos" & $\begin{array}{c}\text { Porcentaje sobre } \\
\text { el total }\end{array}$ \\
\hline PACMA & 226469 & 100 \\
\hline Recortes Cero & 34306 & 100 \\
\hline Por un Mundo + Justo & 27016 & 100 \\
\hline Bloque Nacionalista & 61832 & 52 \\
\hline Galego & 202791 & 51 \\
\hline Más País & 765046 & 47 \\
\hline Ciudadanos & 53511 & 31 \\
\hline Més Compromís & 67326 & 28 \\
\hline CUP & 465266 & 18 \\
\hline Unidas Podemos & 341259 & 9 \\
\hline Vox & 172892 & 3 \\
\hline Partido Popular & 16183 & 3 \\
\hline En Comú Podem & 15449 & 0 \\
\hline PSOE & & \\
\hline
\end{tabular}

Nota: Elaborada a partir de los datos del Ministerio del Interior.

\footnotetext{
${ }^{10}$ Por el interés científico de la comparación se incluyen también otros partidos sin representación pero con un número de votos relevante, como PACMA.
} 


\section{DERECHO EIECTORAL}

SEGUNDO SEMESTRE 2021 NUMMERO 32

El sistema electoral del Congreso de Diputados español...

Tabla 3

Diferencias entre las proporciones de votos y de escaños de los principales partidos en elecciones generales, 1977-2019

\begin{tabular}{|c|c|c|c|c|c|c|c|c|c|c|c|}
\hline \multirow[b]{2}{*}{ Elección } & \multicolumn{11}{|c|}{ Partidos } \\
\hline & $\begin{array}{c}\text { PCE/ } \\
\text { IU }\end{array}$ & UP & PSOE & CDS & UCD & UPyD & Cs & AP/PP & $\begin{array}{c}\mathrm{CiU} / \\
\text { JxCat }\end{array}$ & PNV & VOX \\
\hline 1977 & $-3,6$ & & 4,4 & & 12,9 & & & $-3,8$ & $-0,6$ & 0,6 & \\
\hline 1979 & $-4,2$ & & 4,1 & & 12,9 & & & $-3,5$ & $-0,5$ & 0,4 & \\
\hline 1982 & $-2,4$ & & 10,4 & $-2,2$ & $-3,1$ & & & 4,7 & $-0,2$ & 0,5 & \\
\hline 1986 & $-2,7$ & & 8,5 & $-3,8$ & & & & 3,9 & 0,1 & 0,2 & \\
\hline 1989 & $-4,3$ & & 10,4 & $-3,9$ & & & & 4,8 & 0,1 & 0,2 & \\
\hline 1993 & $-4,5$ & & 6 & & & & & 5,5 & 0 & 0,2 & \\
\hline 1996 & $-4,6$ & & 2,8 & & & & & 5,7 & 0 & 0,1 & \\
\hline 2000 & $-3,2$ & & 1,6 & & & & & 7,8 & 0,1 & 0,5 & \\
\hline 2004 & $-3,5$ & & 4,2 & & & & & 4,6 & $-0,4$ & 0,4 & \\
\hline 2008 & $-3,2$ & & 4,6 & & & $-0,9$ & & 3,6 & $-0,1$ & 0,5 & \\
\hline 2011 & $-3,8$ & & 2,7 & & & $-3,3$ & & 8,5 & $-0,4$ & 0,1 & \\
\hline 2015 & $-3,1$ & $-0,95$ & 3,7 & & & & $-2,5$ & 6,4 & 0 & 0,5 & \\
\hline 2016 & & $-0,8$ & 1,3 & & & & $-3,9$ & 6,1 & 0,3 & 0,2 & \\
\hline 2019 (a) & & $-2,3$ & 6,5 & & & & 0,4 & 2,2 & 0,1 & 0,2 & $-3,4$ \\
\hline $2019(n)$ & & $-2,8$ & 6,3 & & & & $-3,9$ & 4,3 & 0,1 & 0,43 & $-0,2$ \\
\hline
\end{tabular}

Nota: Elaborada hasta 2016 partiendo de Montero y Fernández (2018). Actualizada según los datos del Ministerio del Interior.

Finalmente, uno de los factores más significativos del sistema electoral del Congreso de los Diputados español es su consonancia con las preferencias de los electores, que se plasma en una baja fragmentación del sistema de partidos hasta 2015 -con un bipartidismo imperfecto de dos partidos y medio $y$, consecuentemente, gran estabilidad gubernamental-, y un claro multipartidismo tras el auge de las nuevas formaciones a partir de las elecciones de diciembre de 2015. Ello es fácilmente comprobable al analizar la evolución del número efectivo de partidos electorales (NEPE) - que pondera el número de partidos que concurren a las elecciones con el número de votos que obtienen- y el número efectivo de partidos parlamentarios (NEPP) -que pondera el número de partidos que concurren a las elecciones con el número de escaños que obtienen- (figura 4). 


\section{DERECHO EIECTORAL}

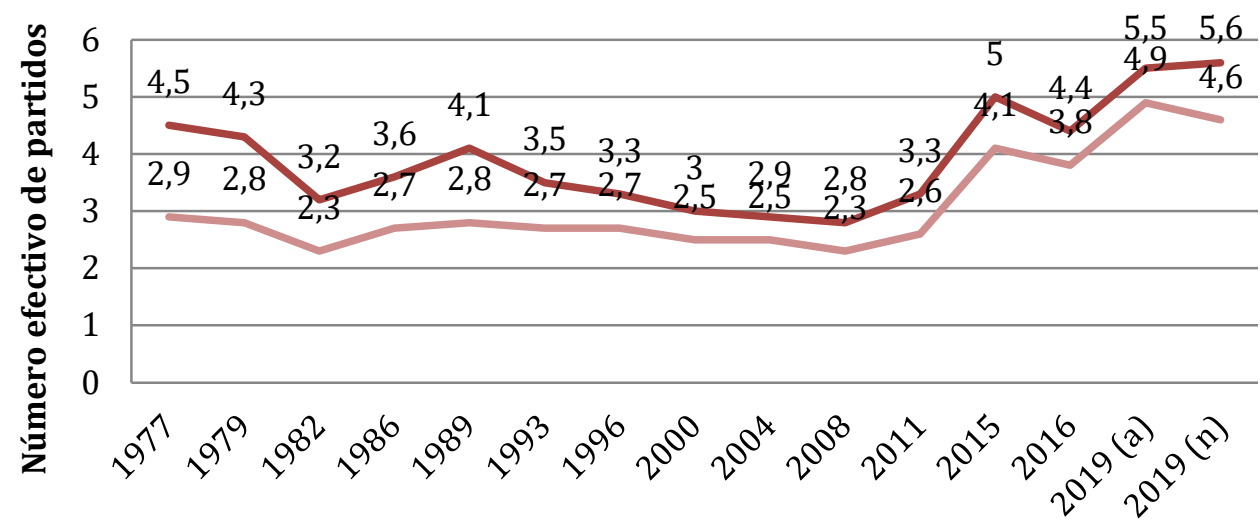

Año de las elecciones

$\longrightarrow \mathrm{NEPE} \longrightarrow \mathrm{NEPP}$

Figura 4. Evolución del NEPE y NEPP desde el comienzo de la democracia hasta la actualidad. Elaborado a partir de Laakso y Taagepera (1979) con datos del Ministerio del Interior.

\section{Evaluación CONClUSiva del Sistema electoral ACtUAL}

A la luz de lo expuesto podemos evaluar el sistema electoral español considerando sus diferentes elementos articuladores.

Innegablemente, la arquitectura electoral española ha derivado en una amplia representación sociodemográfica en el Congreso (aspirando a una "representación espejo" de los territorios, en términos de Hanna Pitkin [2014, p. 85]), habida cuenta de la entrada de 10 partidos de corte regionalista o nacionalista en la cámara y sin perjuicio de la presencia mayoritaria de los partidos hegemónicos: PSOE y PP (efecto mecánico no tan incidente como en las elecciones previas a 2015). Ello demuestra una precisa traslación a las Cortes Generales de las preferencias de los votantes, en tanto hay un gran número de partidos que han obtenido escaños, si bien el sistema de listas cerradas y bloqueadas impide una mayor maximización del turnout (participación electoral).

En las circunscripciones pequeñas, como se ha ilustrado, aumenta la importancia de los efectos psicológicos, especialmente del voto útil - de partido y de gobierno- y de la coalición preelectoral para concentrar sufragios. Sin embargo, el efecto de la accountability ha sido parcial, por cuanto los resultados se asemejaron -a excepción del caso de Ciudadanos- a los de las elecciones de abril, repitiéndose las mismas candidaturas en la mayoría de las circunscripciones. 


\section{DERECHO EIECTORAL}

La principal novedad de los comicios del $10-\mathrm{N}$ fue que derivaron en el primer Ejecutivo de coalición desde la restitución de la democracia en España. Esta coalición -de tipo minoritario- ha derivado en la necesidad de pactar tanto ad extra como ad intra del Consejo de Ministros, circunstancia que cobra un especial interés atendiendo al aludido gran número de partidos regionalistas y nacionalistas. Este contexto está poniendo de relieve la importancia de la representación territorial en el Congreso, dejando en un todavía más discreto segundo plano a la ya minusvalorada cámara alta.

Lo indicado permite concluir con una paradoja de difícil resolución: la práctica totalidad de los partidos -a excepción de PSOE y PP-, y especialmente los de reciente aparición, proponen modificaciones en el sistema electoral (véase el apartado siguiente), pero estas difícilmente se llevarán a cabo por las mayorías requeridas para reformar la LOREG y, en su caso, la CE. De este modo, mientras que los partidos nacionalistas se opondrán a la circunscripción única, los partidos que protagonizaron el bipartidismo hasta 2015 rechazarán la proporcionalidad pura, reclamada a su vez por las formaciones minoritarias. Todo ello puede fundamentar una última idea: quizá la versatilidad del sistema electoral en el paso a esta nueva etapa política es muestra de su validez y vigencia para el futuro.

\section{ApÉndice: Simulación de RESUltados Siguiendo las PRINCIPALES PROPUESTAS DE REFORMA ${ }^{11}$}

Partiendo de los resultados en votos de las elecciones al Congreso de los Diputados de noviembre de 2019, en este apéndice se pretende mostrar la conformación que tendría la cámara baja española si se modificaran distintos elementos del sistema electoral. De entre las muchas propuestas de reforma realizadas por la doctrina se han seleccionado 19 siguiendo el informe del Consejo de Estado sobre las propuestas de modificación del régimen electoral general (2009).

11 Todas las simulaciones se han realizado partiendo de los resultados definitivos del Ministerio del Interior. Agradezco la desinteresada e imprescindible labor de Eduardo González Vaquero, matemático de la Universidad Complutense de Madrid, en la configuración de la plataforma Brainum, software informático utilizado para realizar las simulaciones. 


\section{DERECHO ELECTORAL}

1- Sistema electoral actual:

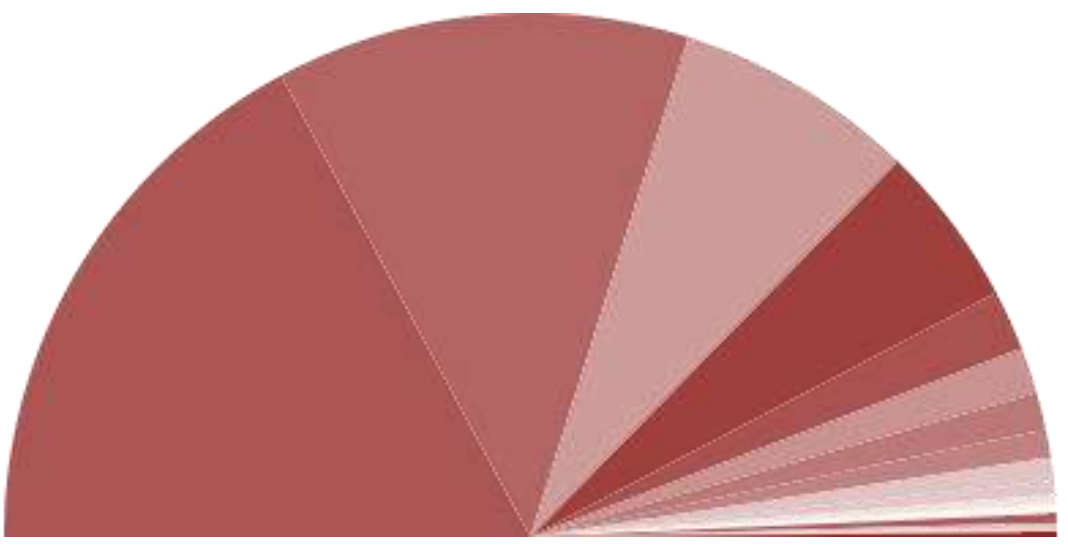

\begin{tabular}{|c|c|c|c|c|c|c|}
\hline PSOE & $\square P P$ & aOX & 口UP & 口 ERC & $\square \mathrm{Cs}_{5}$ & DxCAT \\
\hline EH Bildu & Más Páis & $\mathrm{Cl}$ & $\mathrm{NC}-\mathrm{CCA}$ & NAt & BNG & PRC \\
\hline
\end{tabular}

Resultados en escaños: PSOE 120, PP 89, VOX 52, UP 36, ERC 13, Cs 10, JxCat 8, PNV 6, EH Bildu 5, MP 2, CUP 2, NC-CCA 2, NA+ 2, BNG 1, PRC 1, TE 1.

2- Fórmula $\mathrm{D}^{\prime} \mathrm{Hondt}^{12}{ }^{12}$ umbral del $3 \%$ y circunscripción única:

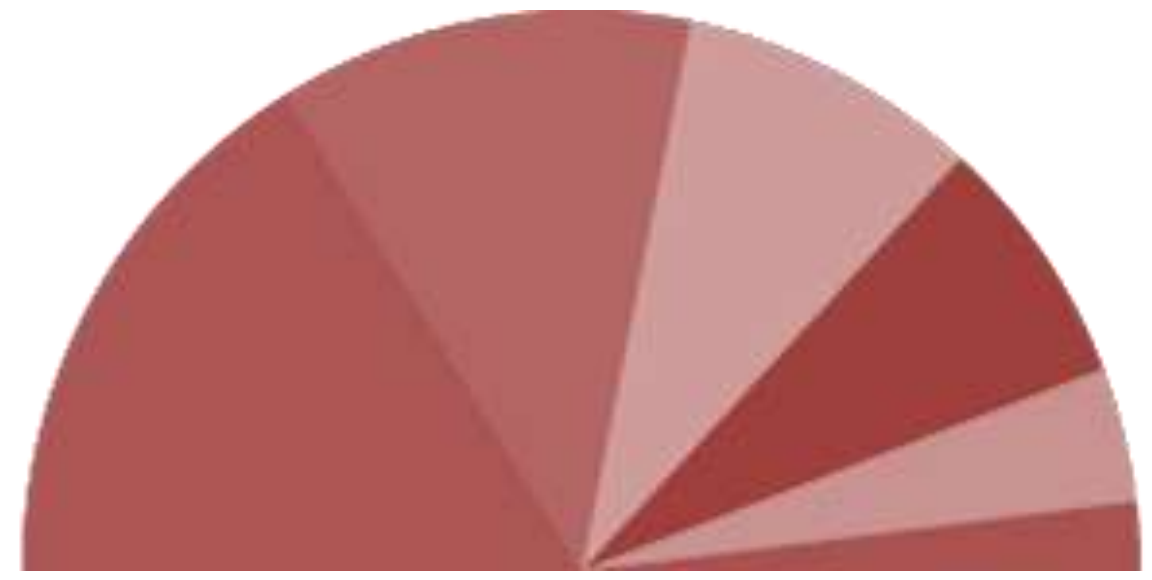

Resultados y variación de escaños: PSOE $113(-7)$, PP 85 (-4), VOX 61 (+9), UP 51 $(+16)$, Cs $27(+17)$, ERC $14(+1)$. Los demás partidos políticos perderían su representación en el Congreso.

\footnotetext{
${ }^{12} q=m / n+1$, con $q$ aproximado al entero más cercano, siendo $m$ los votos y $n$ los escaños.
} 


\section{DERECHO ELECTORAL}

SEGUNDO SEMESTRE 2021 NULMERO 32

El sistema electoral del Congreso de Diputados español...

3-Fórmula D’Hondt, sin umbral y circunscripción única:

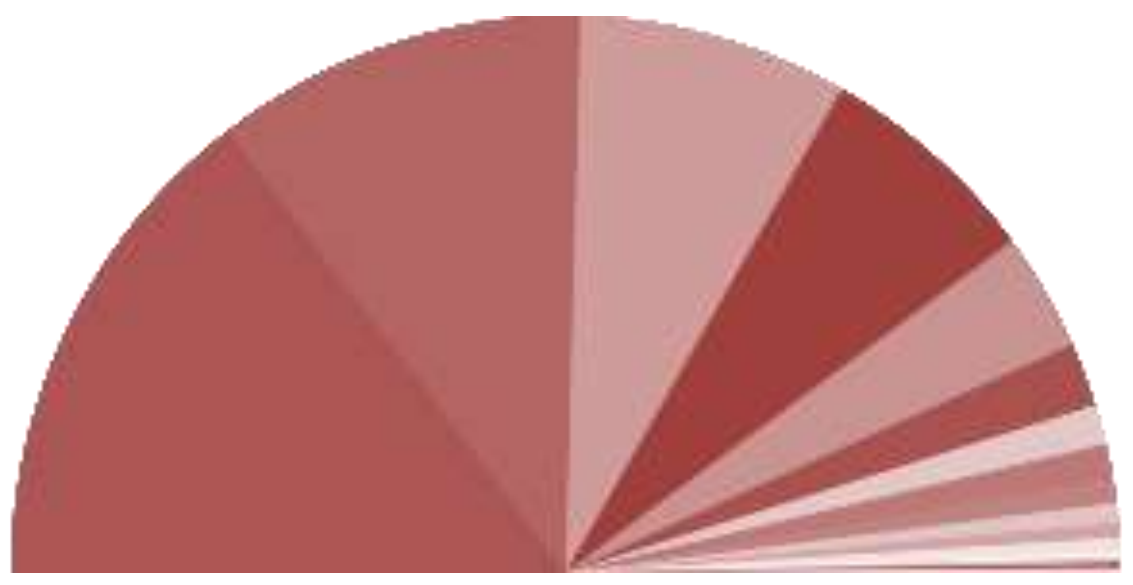

Resultados y variación de escaños: PSOE $102(-18)$, PP $77(-12)$, VOX $55(+3)$, UP $47(+11)$, Cs $24(+14)$, ERC $13(=)$, MP $7(+5)$, JxCAT $7(-1)$, PNV $4(-2)$, EH Bildu $5(=)$, PACMA $3(+3)$, CUP $3(+1)$, NC-CCA $1(-1)$, BNG $1(=), \mathrm{NA}+1(-1)$, PRC 1 $(=)$. Teruel Existe (TE) perdería su representación en el Congreso.

4- Fórmula D’Hondt, umbral del $4 \%{ }^{13}$ y circunscripción única:

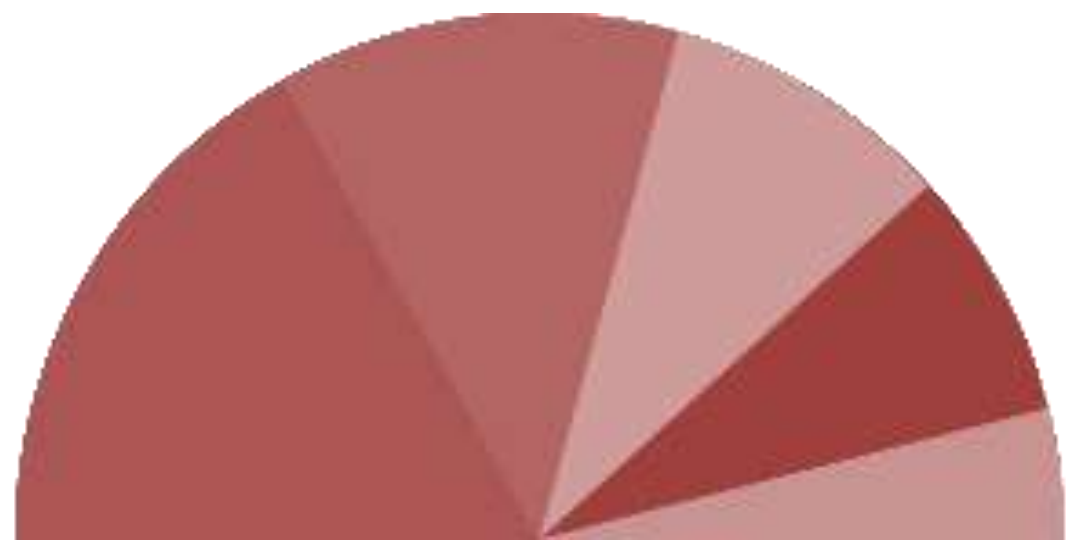

Resultados y variación de escaños: PSOE $118(-2)$, PP $88(-1)$, VOX 63 (+11), UP 55 (+19), Cs 28 (+18). Los demás partidos políticos perderían su representación en el Congreso.

\footnotetext{
${ }^{13}$ A partir del $4 \%$ de umbral electoral desaparecen todos los partidos regionalistas y nacionalistas.
} 


\section{DERECHO ELECTORAL}

\section{Miguel Ángel Sevilla Duro}

5- Winner Takes It $A / I^{14}$, umbral del 3\% (si bien resulta indiferente), y circunscripción provincial:

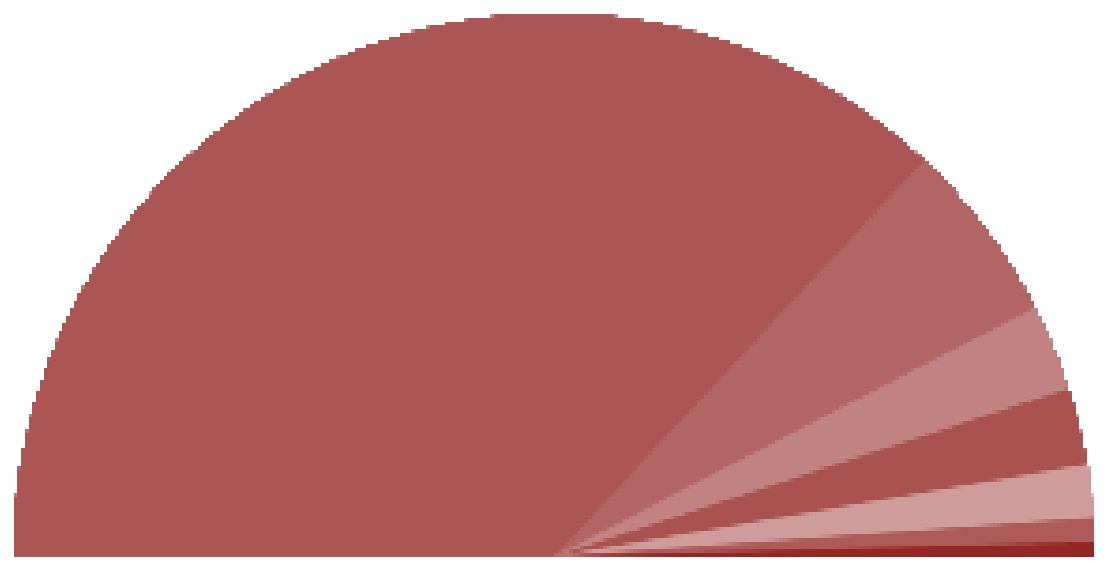

Resultados y variación de escaños: PSOE $259(+139)$, PP $49(-50)$, PNV $17(+11)$, ERC $15(+2)$, VOX $11(-41)$, NA+ $5(+3)$, TE $3(+2)$. Los demás partidos políticos perderían su representación en el Congreso.

6- Winner Takes It All, umbral del 3\% (si bien resulta indiferente), y circunscripción única:

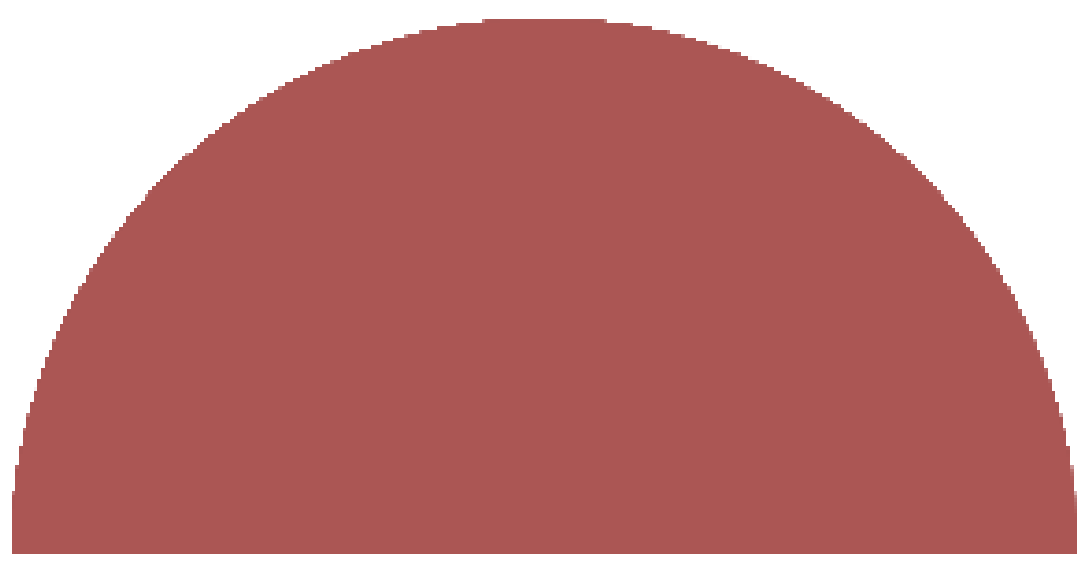

Resultados y variación de escaños: PSOE 350 (+230). Los demás partidos políticos perderían su representación en el Congreso.

\footnotetext{
${ }^{14}$ Sistema mayoritario puro.
} 


\section{DERECHO ELECTORAL}

7- Fórmula Sainte-Lagüe ${ }^{15}$, umbral del $3 \%$ y circunscripción provincial:

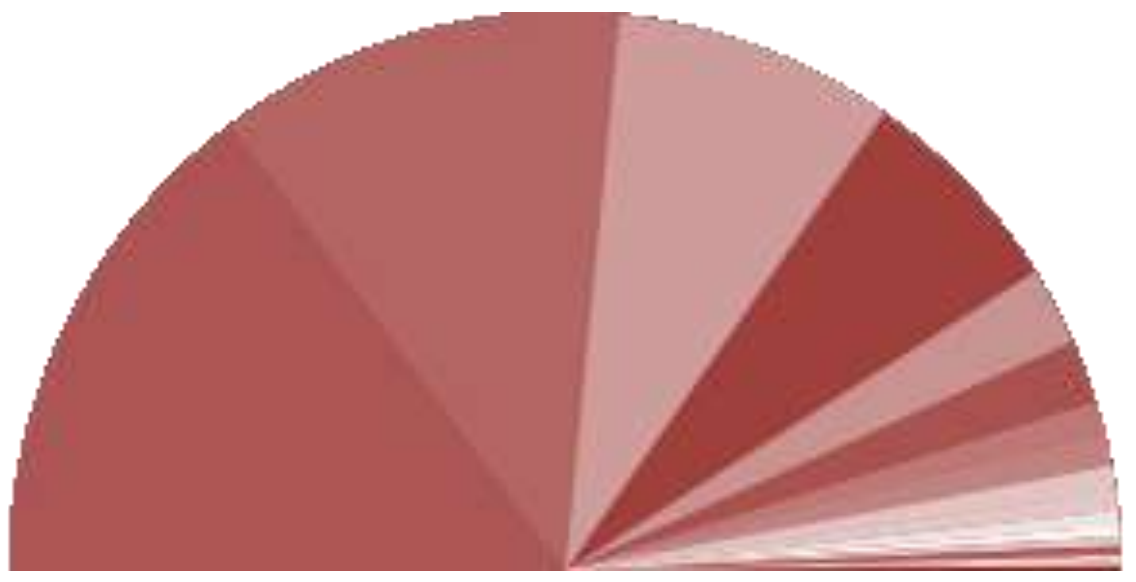

Resultados y variación de escaños: PSOE $103(-17)$, PP $84(-5)$, VOX 55 (+3), UP 45 $(+9)$, Cs $16(+6)$, ERC $13(=)$, JxCat $7(-1)$, PNV $7(+1)$, EH Bildu $5(=)$, MP $3(+1)$, CUP $2(=)$, NC-CCA $2(=)$, BNG $2(+1), \mathrm{NA}+2(=), \operatorname{PRC} 1(=)$, NCa $1(+1)$, TE 1 $(=)$.

8- Fórmula Sainte-Lagüe, umbral del 3\% y circunscripción única:

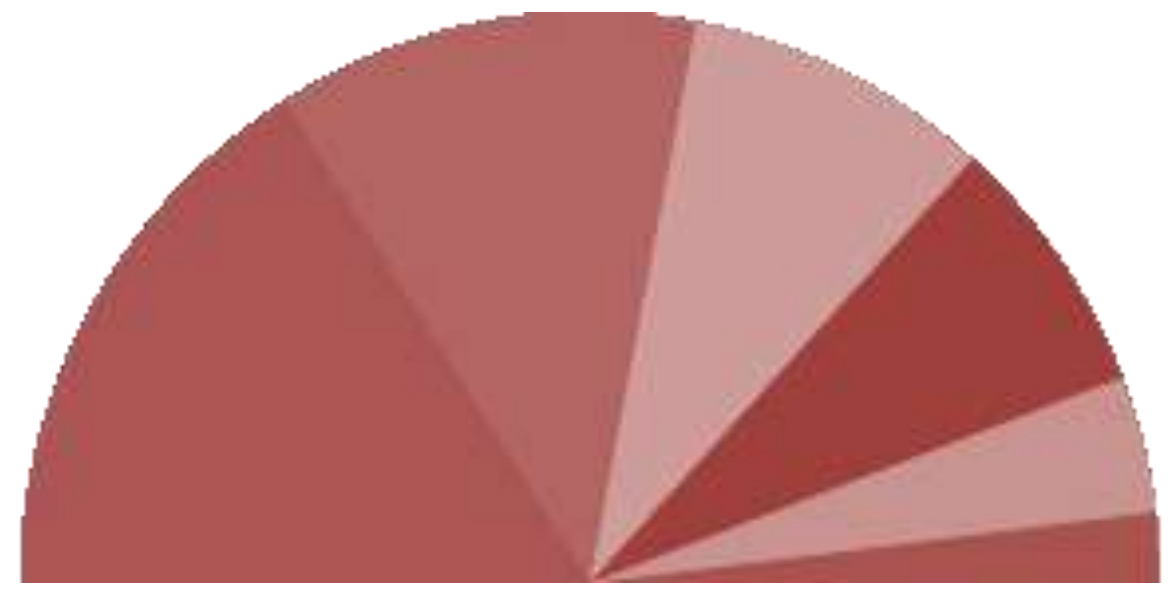

Resultados y variación de escaños: PSOE $112(-8)$, PP 85 (-4), VOX 61 (+9), UP 53 $(+17)$, Cs $27(+17)$, ERC $14(+1)$. Los demás partidos políticos perderían su representación en el Congreso.

\footnotetext{
${ }^{15} q=m /(2 n+1)$, con $q$ aproximado al entero más cercano.
} 


\section{DERECHO ELECTORAL}

\section{Miguel Ángel Sevilla Duro}

9- Fórmula Sainte-Lagüe, umbral del 4\% y circunscripción única:

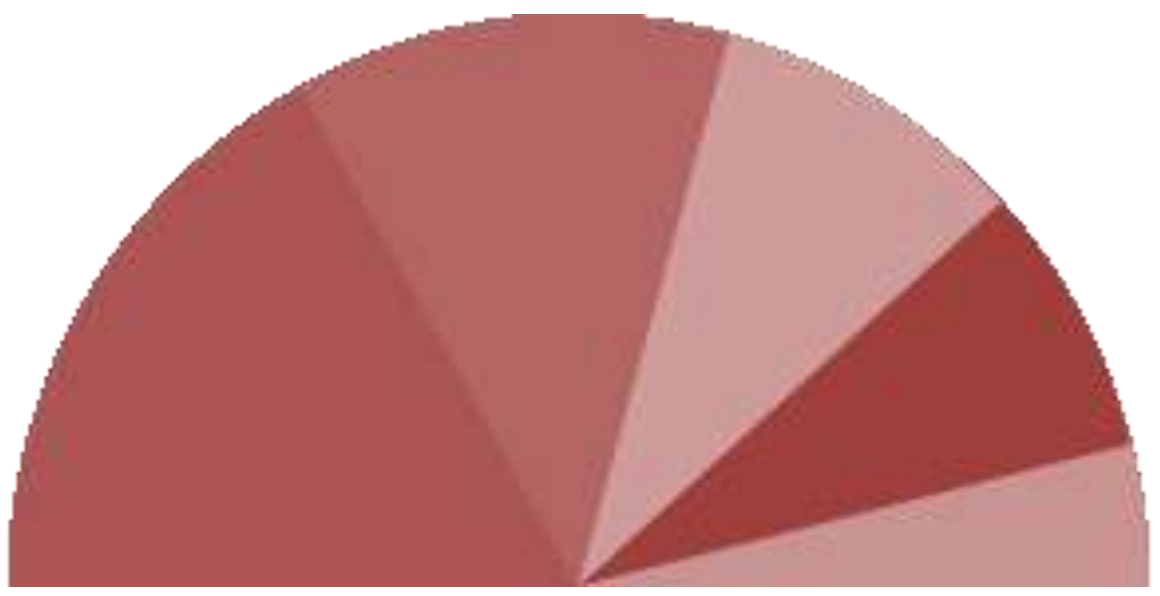

Resultados y variación de escaños: PSOE $118(-2)$, PP 88 (-1), VOX $63(+11)$, UP 55 $(+19)$, Cs $28(+18)$. Los demás partidos políticos perderían su representación en el Congreso.

10- Fórmula Sainte-Lagüe modificada ${ }^{16}$, umbral del $3 \%$ y circunscripción provincial:

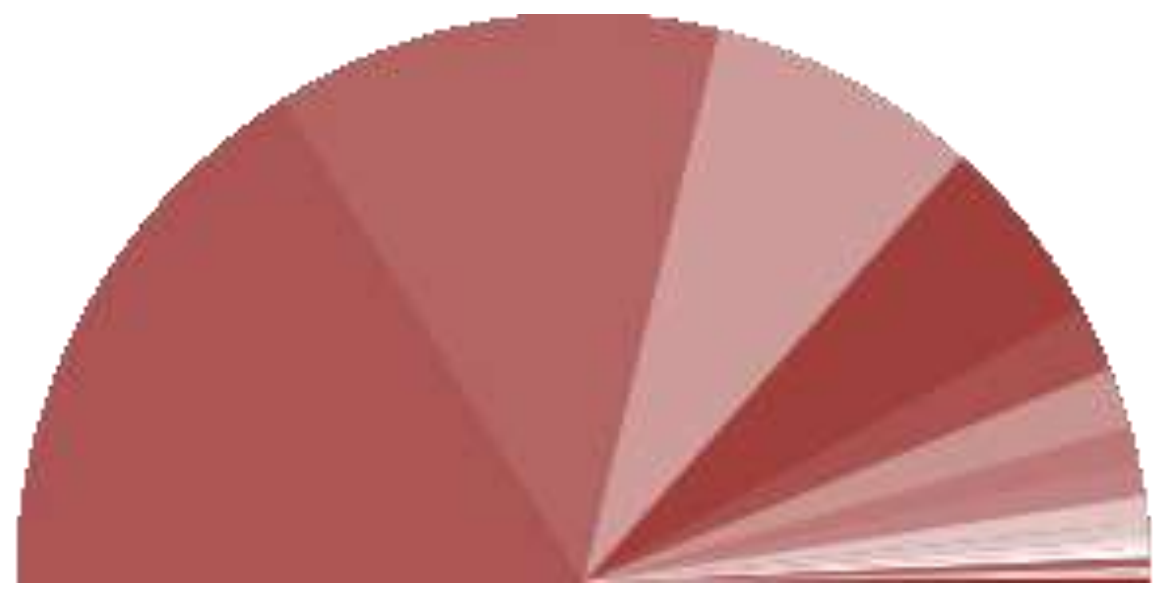

Resultados y variación de escaños: PSOE $113(-7)$, PP $90(+1)$, VOX $54(+2)$, UP 38 $(+3), \operatorname{ERC} 13(=), \operatorname{Cs} 12(+2)$, JxCAT $9(+1)$, PNV $6(=), \operatorname{MP} 2(=)$, CUP $1(-1)$, NCCCA $2(=), \mathrm{NA}+2(=), \mathrm{BNG} 1(=), \operatorname{PRC} 1(=), \mathrm{TE} 1(=)$.

\footnotetext{
${ }^{16} q=m / 1,4$, con $q$ aproximado al entero más cercano en el primer escaño, y a partir de este, usando la fórmula del método puro expuesta en la nota anterior.
} 


\section{DERECHO ELECTORAL}

11- Fórmula Sainte-Lagüe modificada, umbral del 3\% y circunscripción única:

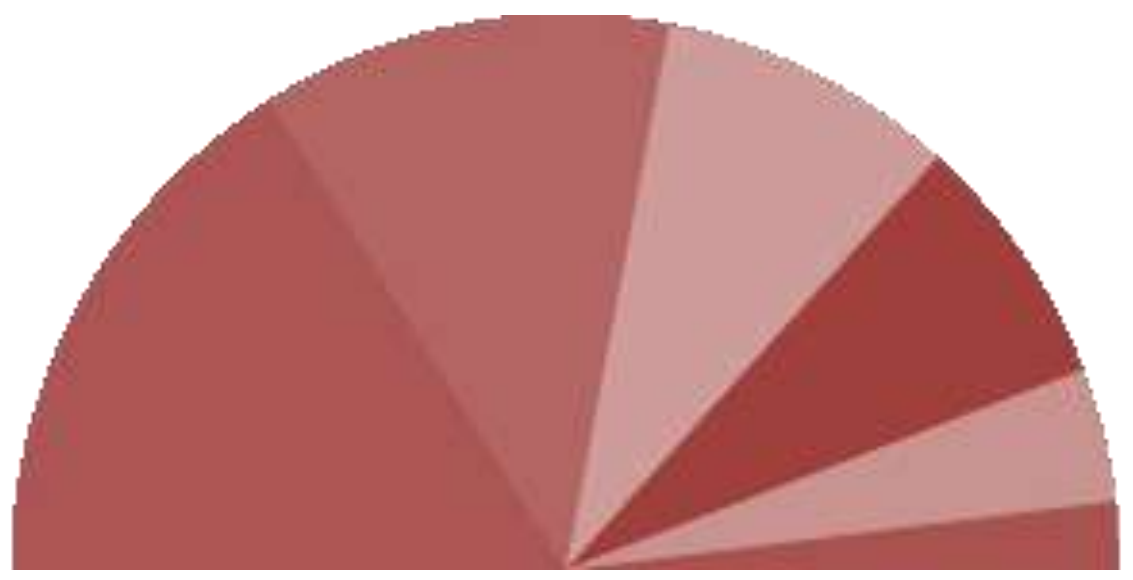

Resultados y variación de escaños: PSOE $112(-8)$, PP 85 (-4), VOX 61 (+9), UP 53 $(+17)$, Cs $27(+17)$, ERC $14(+1)$. Los demás partidos políticos perderían su representación en el Congreso.

12- Fórmula Sainte-Lagüe modificada, umbral del 4\% y circunscripción única:

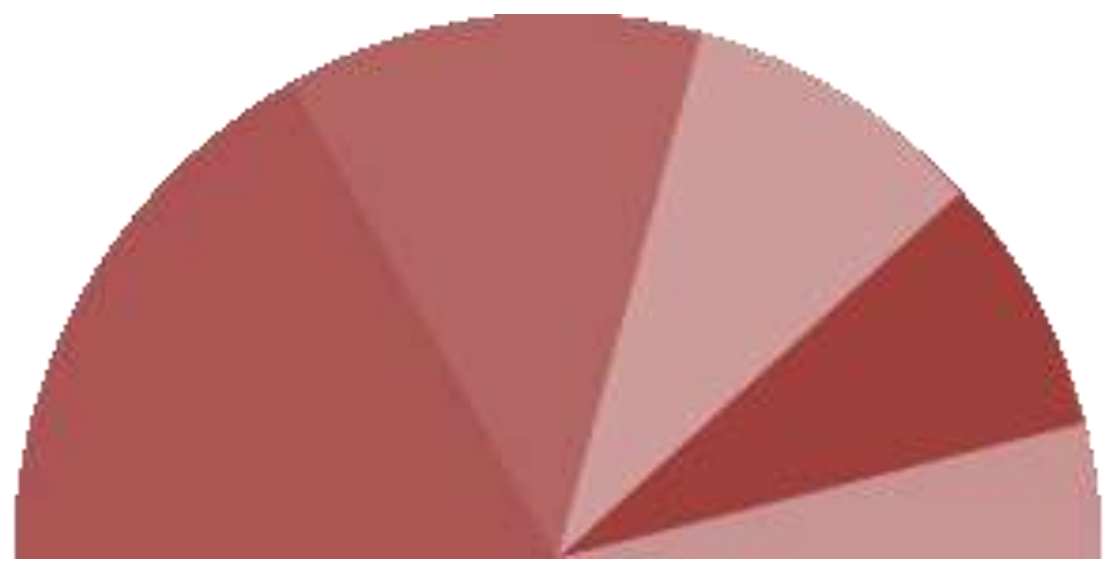

Resultados y variación de escaños: PSOE $118(-2)$, PP $88(-1)$, VOX $63(+11)$, UP 55 $(+19)$, Cs $28(+18)$. Los demás partidos políticos perderían su representación en el Congreso. 


\section{DERECHO ELECTORAL}

\section{Miguel Ángel Sevilla Duro}

13- Cuota Hare ${ }^{17}$, umbral del 3\% y circunscripción provincial:

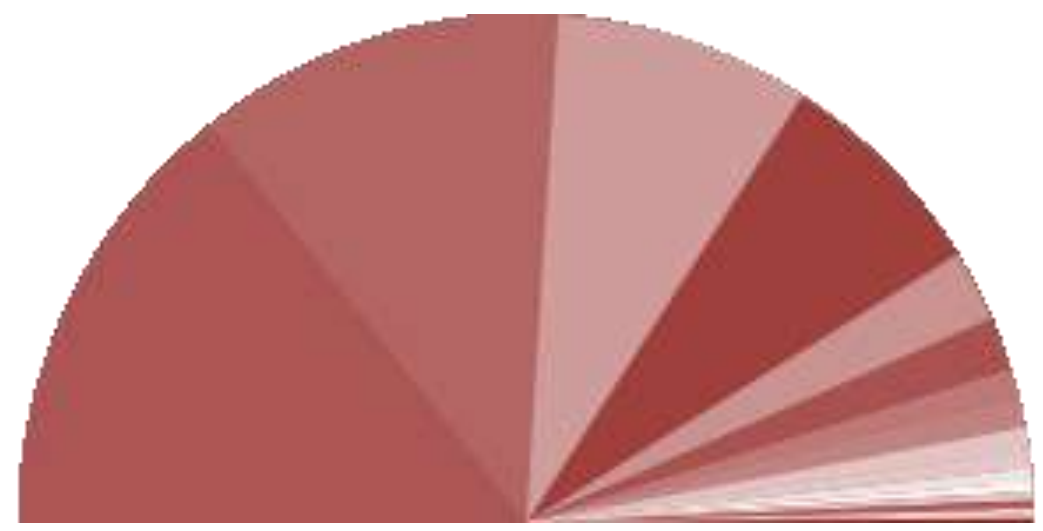

Resultados y variación de escaños: PSOE $100(-20)$, PP $81(-8)$, VOX $57(+5)$, UP 50 $(+14)$, Cs $16(+6)$, ERC $12(-1)$, JXCAT $7(-1)$, PNV (=), EH BILDU $5(=)$, MP 3 $(+1), \operatorname{CUP} 2(=), \mathrm{NC}-\mathrm{CCA} 2(=), \mathrm{BNG} 2(+1), \mathrm{NA}+2(=), \mathrm{PRC} 1(=), \mathrm{NCa} 1(+1), \mathrm{TE}$ $1(=)$.

14- Cuota Hare, umbral del 3\% y circunscripción única:

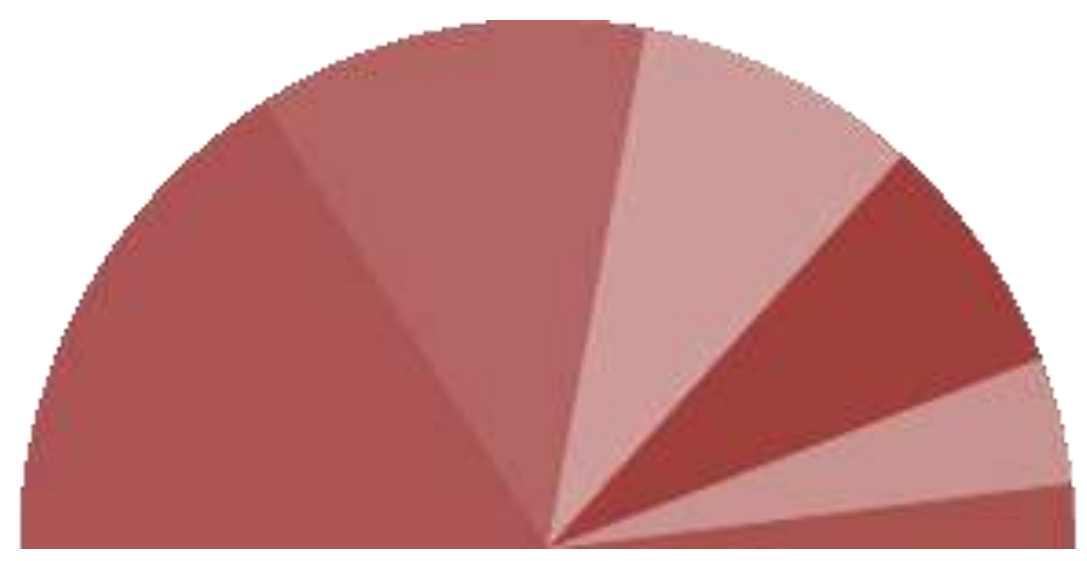

Resultados y variación de escaños: PSOE $112(-8)$, PP 85 (-4), VOX 61 (+9), UP 53 $(+17)$, Cs $27(+17)$, ERC $13(=)$. Los demás partidos políticos perderían su representación en el Congreso.

\footnotetext{
${ }^{17} q=m / n$, con $q$ aproximado al entero más cercano.
} 


\section{DERECHO ELECTORAL}

15- Cuota Hare, umbral del 4\% y circunscripción única:

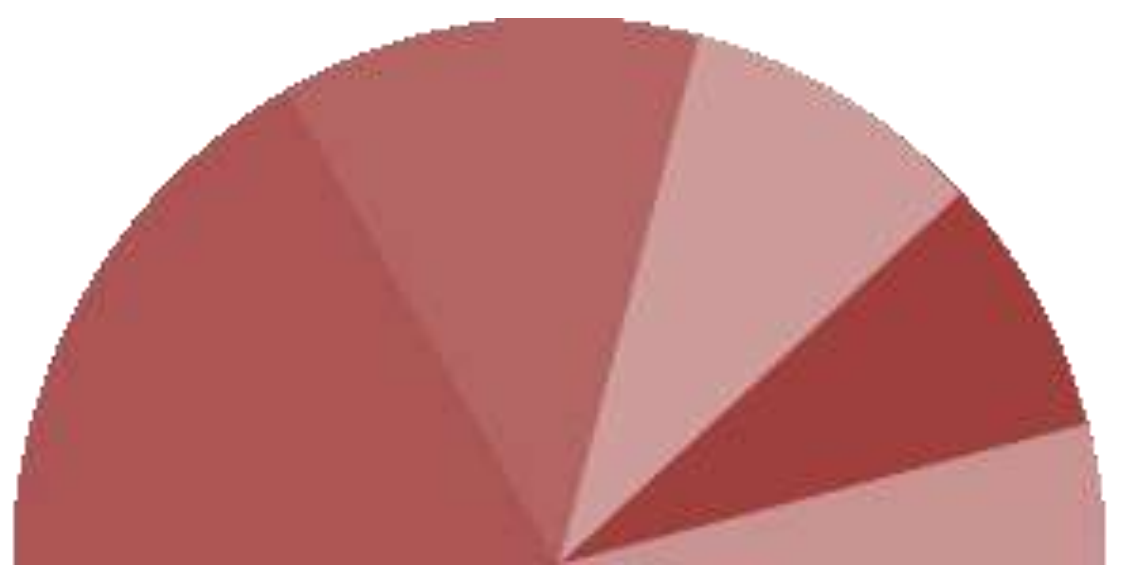

Resultados y variación de escaños: PSOE $117(-3)$, PP 88 (-1), VOX 63 (+11), UP 55 $(+19)$, Cs 29 (+19). Los demás partidos políticos perderían su representación en el Congreso.

16- Cuota Imperiali ${ }^{18}$, umbral del 3\% y circunscripción provincial:

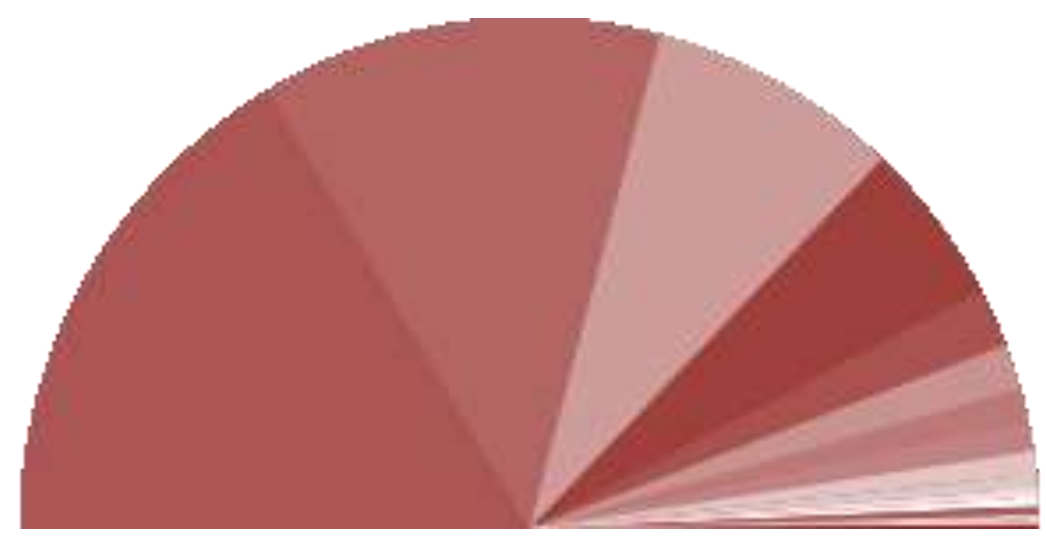

Resultados y variación de escaños: PSOE $115(-5)$, PP $90(+1)$, VOX $56(+4)$, UP 37 $(+1)$, ERC $13(=), \operatorname{Cs} 10(=)$, JxCAT $8(=)$, PNV $5(-1)$, EH BILDU $5(=)$, MP $2(=)$, CUP $2(=), \operatorname{NA}+2(=)$, BNG $1(=)$, PRC $1(=)$, TE $1(=)$.

\footnotetext{
${ }^{18} q=m /(n+2)$, con $q$ aproximado al entero más cercano.
} 


\section{DERECHO ELECTORAL}

17- Cuota Imperiali, umbral del 3\% y circunscripción única:

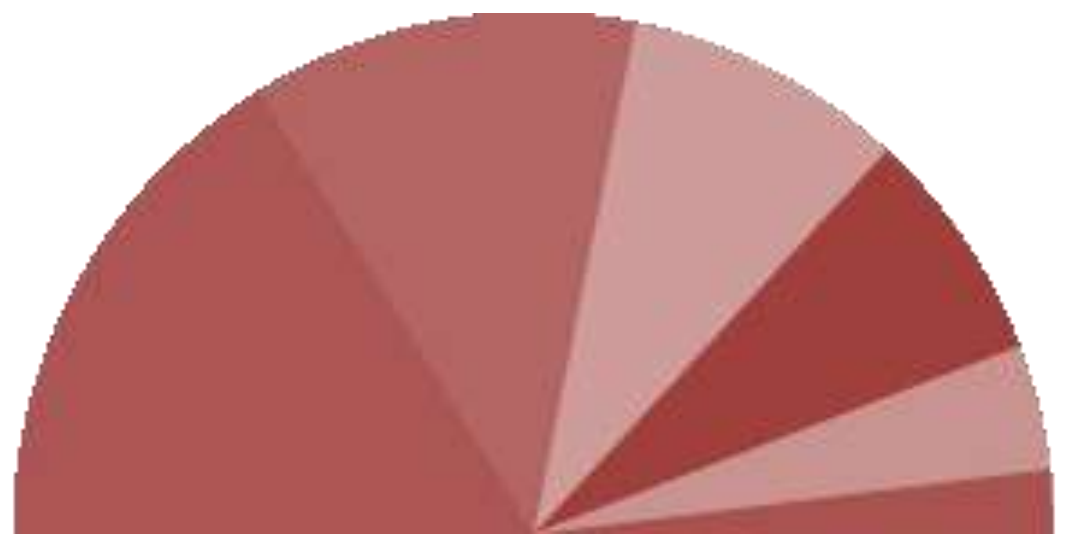

Resultados y variación de escaños: PSOE $113(-7)$, PP 85 (-4), VOX 61 (+9), UP 52 $(+17)$, Cs $27(+17)$, ERC $14(+1)$. Los demás partidos políticos perderían su representación en el Congreso.

18- Cuota Hagenbach-Bischoff ${ }^{19}$, umbral del 3\% y circunscripción única:

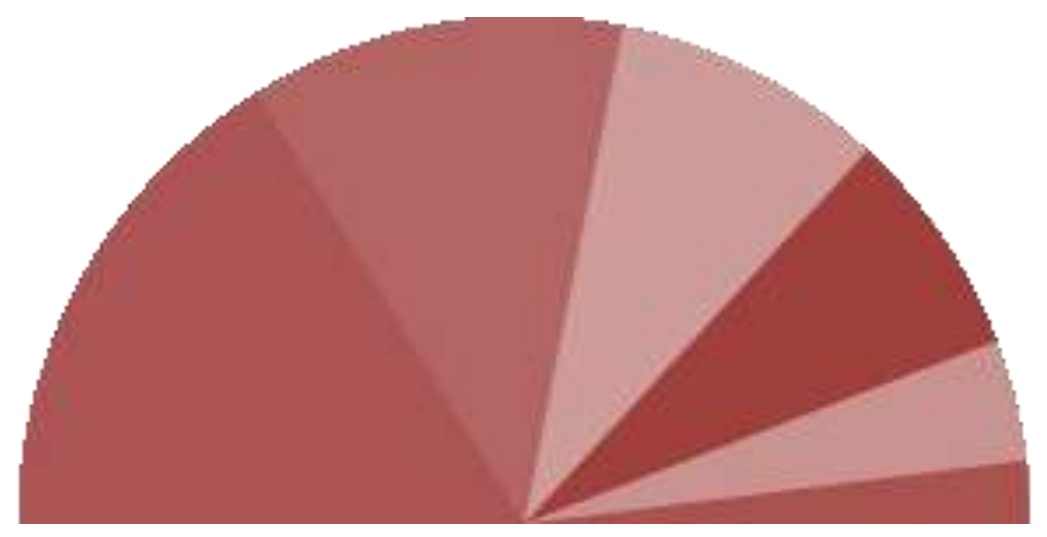

Resultados y variación de escaños: PSOE $113(-7)$, PP 85 (-4), VOX 61 (+9), UP 52 $(+17)$, Cs $27(+17)$, ERC $14(+1)$. Los demás partidos políticos perderían su representación en el Congreso.

${ }^{19} q=m /(n+1)$, con $q$ aproximado al entero más cercano. 


\section{DERECHO ELECTORAL}

19- Cuota Hagenbach-Bischoff, umbral del 3\% y circunscripción provincial:

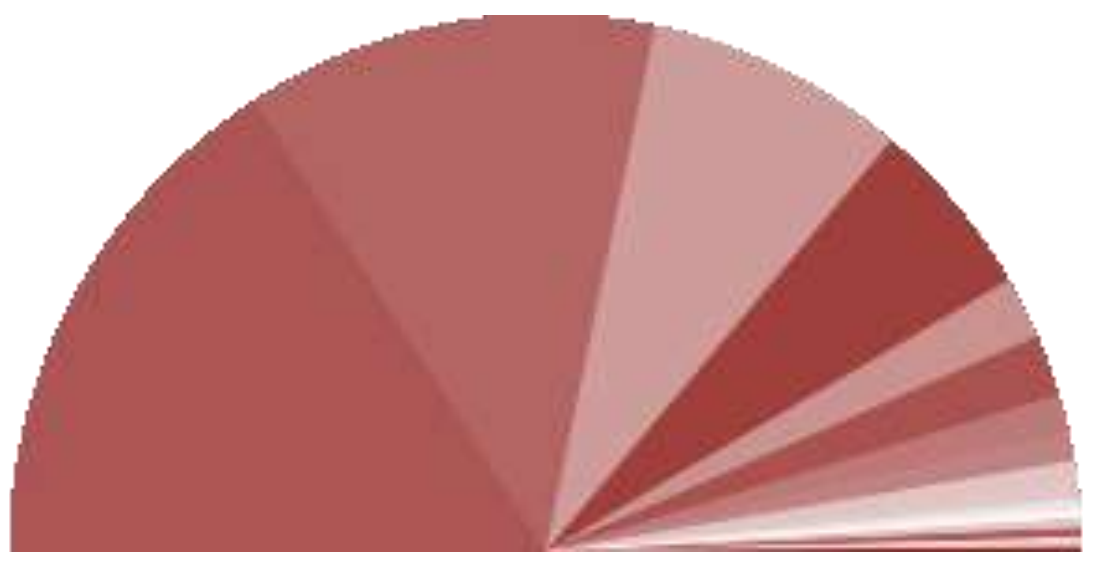

Resultados y variación de escaños: PSOE $111(-9)$, PP $88(-1)$, VOX $55(+3)$, UP 38 $(+3)$, Cs $13(+3)$, ERC $13(=)$, JxCAT $8(=), \operatorname{PNV} 6(=)$, EH BILDU $5(=), \operatorname{MP} 3(=)$, CUP $2(=)$ NC-CCA $2(=), \mathrm{NA}+2(=)$, BNG $2(+1), \operatorname{PRC} 1(=), \mathrm{NCa} 1(+1)$, TE 1 $(=)$.

\section{REFERENCIAS BIBLIOGRÁFICAS}

Almagro, D. (2018). La apertura de las listas electorales: ¿un primer paso hacia la superación de la crisis de representatividad en la democracia española? Revista Española de Derecho Constitucional (112), 115-143.

Alzaga, O. (1989). I rapporti tra Capo dello Stato, Governo e Parlamento. En Rolla, Giancarlo, ed., Il X anniversario della Constituzione spagnola: bilancio, problemi, prospettive. Siena: Centro Stampa della Facoltà di Scienze Economiche i Bancarie.

Arnaldo, E. (2019). El funcionamiento del sistema electoral español. Revista Derecho Electoral (28), 177-183.

Caciagli, M. (1986). Elecciones y partidos en la transición española. Madrid: Centro de Investigaciones Sociológicas.

Colomer, J. M. (2004). Breve historia del sistema electoral en España. Claves de Razón Práctica (140), 34-39.

España. Consejo de Estado (2009). Informe del Consejo de Estado sobre las propuestas de modificación del régimen electoral general. 


\section{DERECHO ELECTORAL}

España (Norma) (1978). Constitución española. Publicada en el Boletín Oficial del Estado el 29 de diciembre de 1978. Recuperada de https://www.boe.es/eli/es/c/1978/12/27/(1)/con

España (Norma) (1985). Ley Orgánica 5/1985, de 19 de junio, del Régimen Electoral General. Publicada en el Boletín Oficial del Estado el 20 de junio de 1985. Recuperada de https://www.boe.es/eli/es/lo/1985/06/19/5/con

España. Ministerio del Interior (2019). Elecciones generales de 10 de noviembre de 2019. Fichas de análisis electoral. Recuperado de http://www.interior.gob.es/documents/10180/11113854/DossierEleccionesLogistica.pd f/26b84fc9-44ad-45ac-8552-0c686c73d1e7

García, J. L. (2017). La organización del pueblo: Los sistemas electorales. En D. López, M. F. Massó, y L. Pegoraro (dirs.), Derecho Constitucional Comparado. Valencia: Tirant Lo Blanch.

Laakso, M. y Taagepera, R. (1979). 'Effective' Number of Parties: A Measure with Application to West Europe. Comparative Political Studies (12), 3-27.

Montabes, J. y Ortega, C. (2002). El voto limitado en las elecciones al Senado español: estrategias de nominación y rendimientos partidistas en las elecciones de marzo de 2000. Revista Española de Ciencia Política (7), 103-130.

Montero, J. R. y Vallès, J. M. (1992). El debate sobre la reforma electoral: ¿para qué las reformas? Claves de Razón Práctica (22), 2-11.

Montero, J. R. y Fernández, C. (2018). Cuatro décadas del sistema electoral español, 19772016. Política y Gobernanza. Revista de Investigaciones y Análisis Político (2), 5-46.

Moreno, C. y Oñate, P. (2004). Tamaño del distrito y voto estratégico en España. Reis $(107), 123-151$.

Nohlen, D. (2004). Sistemas electorales y partidos políticos. México: Fondo de Cultura Económica.

Ong, K-M., Kasuya, Y. y Mori, K. (2017). Malapportionment and Democracy: A Curvilinear Relationship. Electoral Studies (49), 118-227.

Penadés, A. (1999). El sistema electoral español (1977-1996). En J. L. Paniagua y J. C. Monedero (eds.), En torno a la democracia en España. Temas abiertos del sistema político español. Madrid: Tecnos.

Pitkin, H. F. (2014). El concepto de representación. Madrid: Centro de Estudios Políticos y Constitucionales. 


\section{DERECHO ELECTORAL}

Rae, D. W. (1971). The Political Consequences of Electoral Laws. New Haven: Yale University Press.

Real Academia Española (2021). Diccionario panhispánico del español jurídico. Recuperado de https://dpej.rae.es/

Shugart, M. S. y Taagepera, R. (2017). Votes from Seats. Logical Models of Electoral Systems. Cambridge: Cambridge University Press.

Simón, P. (2009). La desigualdad y el valor de un voto: El "malapportionment" de las cámaras bajas en perspectiva comparada. Revista de Estudios Políticos (143), 65-188.

Taagepera, R. (1972). The size of national assemblies. Social Science Research (1/4), 385401.

Vallès, J. M. y Bosch, A. (1997). Sistemas electorales y gobierno representativo. Barcelona: Ariel. 